\title{
Differential size-biased parasitism between Polyacanthorhynchus nigerianus (nomen nudum) and Polyacanthorhynchus echiyensis (nomen nudum) (Acanthocephala: Polyacanthocephala)
}

\section{Paul Chinedu Echi*, Sanil George and Suresh Kumar}

Rajiv Gandhi Center for Biotechnology, Trivandrum, India. *Email: paul_echi@yahoo.com.

\begin{abstract}
Seasonal occurrence of acanthocephalans is replete with controversies stemmed from hosts' activities and environmental conditions etc. Ergo, recent mitochondrial DNA resolved two new cystacanths sequences in a parentenic host Polyacanthorhynchus nigerianus NG1 KC904074 and Polyacanthorhynchus echiyensis NG5 KC9040745 has necessitated the present study between wet and dry seasons. Though the trend of infection followed a similar pattern, NG5 had higher prevalence than NG1 with highest prevalence $5.3 \%$ in January. However, the trend changed from March-July when the occurrence of NG1 had relatively much lower monthly prevalence $\leq 2.6 \%$. Their differential body size NG5 $994.61+110.07 \mathrm{~mm}$ and NG1 $237.58+30.34 \mathrm{~mm}$, respectively, resulted in a trade-off between their body sizes and numbers.
\end{abstract}

Keywords: Abiotic factors; Body size; Mitochondrial DNA; Polyacanthohynchus; Thorny-headed worms; Seasonality; Synodontis batensoda.
Received

November 14, 2015

Accepted

April 12, 2016

Released

June 30, 2016

Open Acess

Full Text Article

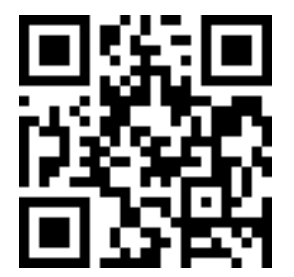

ORCIID

(ㄱ) 0000-0001-5868-1142

Paul Chinedu Echi

(ㄱ) 0000-0001-6542-2931

Sanil George

(D) 0000-0002-9065-8601

Suresh Kumar

\section{Introduction}

Polyacanthocephala as a separate class was first proposed by Schmidt and Canaris (1967) and Bullock (1969), and then more specific characters are being used to support the proposal. Out of the four earlier recognized species Polyacanthorhynchus macrorhynchus
(Diesing, 1856), Polyacanthorhynchus caballeroi Diaz-ungria and Rodrigo, 1960, and Polyacanthorhynchus rhopalorhynchus (Diesing, 1851) inhabit the digestive tract of South American caimans whereas the fourth species, Polyacanthorhynchus kenyensis Schmidt and Canaris, 1967 is only known in the larval stage, infecting freshwater fish in Kenya (Amin, 1987). 
Also, recently mitochondrial CO1 gene of two new cystacanths sequences Polyacanthorhynchus nigerianus (nomen nudum) and Polyacanthorhynchus echiyensis (nomen nudum) infecting some parentenic individuals of Synodontis batensoda Rüppell, 1832 in Nigeria were sequenced and compared with the three widely recognized classes of Acanthocephala, namely Archiacanthocephala, Palaeacanthocephala and Eoacanthocephala. It is notable that these two new sequences formed a common clade with P. caballeroi, which is the only representative of the new class Polyacanthocephala in the GenBank/NCBI (Echi et al., 2015).

However, there is little information about the seasonal occurrence of P. macrorhynchus, P. caballeroi, and $P$. rhopalorhynchus. In addition, available information on the seasonal occurrence of $P$. kenyesis among its potential hosts had no perceptible seasonal influence in its occurrence (Amin and Dezfuli, 1995).

The information on the seasonal influence with respect to the occurrence of the two new sequences is inexistent. Therefore, present study was to present the effects of environmental influence of various seasons in their occurrence and size differences in these thorny-headed worms on fish hosts.

\section{Materials and method}

152 individual samples of S. batensoda were randomly collected on monthly basis (September 2012-August 2013) from caught stocks by fishers at Otuocha, Anambra River (06 21' 29” N and $07^{\circ} 52^{\prime} 22 ”$ E), Anambra State, Nigeria, following details in Olaosebikan and Raji (1998).

The abiotic factors - surface water temperature, dissolved oxygen and $\mathrm{pH}$ were determined using details in Echi and Ezenwaji (2010). The standard length (SL) of each sample was measured to the nearest $0.1 \mathrm{~cm}$ with the use of a meter rule and sex determined by dissection and gonad examination. The parasites lengths were obtained using stage and ocular micrometers (Erma Inc., Tokyo, Japan). DNA was extracted from alcohol preserved parasite tissue ( $25 \mathrm{mg}$ ) by using Qiagen DNeasy Blood and Tissue kit. Universal (VF1d \& VR1d) primers were used in the present study for amplifying CO1 gene (Ivanova et al., 2006). PCRs were performed in $25 \mu \mathrm{L}$ reactions consisting of $2.5 \mu \mathrm{L}$ each of 10x PCR buffer, $\mathrm{MgCl}_{2}$ (25 $\mathrm{mM})$ and $0.5 \mu \mathrm{L}$ dNTPs $(2 \mathrm{mM}), 0.25 \mu \mathrm{L}$ of each primer $(10 \mu \mathrm{M}), 1$ unit of AmpliTaq Gold DNA polymerase, $14 \mu \mathrm{L}$ of $\mathrm{dH}_{2} \mathrm{O}$ and $4 \mu \mathrm{L}$ of template DNA (10-20 ng) in a Thermocycler (ABI 9700). The following thermo cycling conditions were used for amplifications: $95^{\circ} \mathrm{C}, 5 \mathrm{~min}, 95^{\circ} \mathrm{C}, 30 \mathrm{~s}$, $54^{\circ} \mathrm{C}, 45 \mathrm{~s}, 72^{\circ} \mathrm{C}, 45 \mathrm{~s}$, for 40 cycles, $72^{\circ} \mathrm{C}, 7 \mathrm{~min}, 4^{\circ} \mathrm{C} \infty$.

The PCR products were visualized on $1 \%$ agarose gels and the most intense products were purified using Exo Sap IT (USB). Bidirectional sequencing was performed using the PCR primers and products were labeled with BigDye Terminator V.3.1 Cycle Sequencing Kit (Applied Biosystems, Inc.) and sequenced in an ABI 3730 capillary sequencer following manufacturer's instructions. The sequences were aligned using ClustalW and potentially misaligned sequences were excluded. The extent of sequence differences between species was calculated averaging pairwise comparisons of sequence differences across all individuals. Pairwise evolutionary distance was determined by the Kimura-2-Parameter Method, using the software programme Mega 5 (Tamura et al., 2011).

The number of polymorphic sites and nucleotide diversity (pi), nucleotide composition and number of transition and transversion between species were determined. Gaps were considered as missing data on the phylogenetic reconstructions. Neighbour Joining (NJ) tree was constructed to show intraspecific and interspecific relationships among the new sequences and related sequences in GenBank/NCBI. 


\section{Results}

Comparatively, there is a significant difference between the two parasites. Also, P. echiyensis had more population 222 (162 from males and 60 from females hosts) than $P$. nigerianus 114 (85 from males and 29 from females hosts) (Table 1) and relatively occupied the small intestine more whereas $P$. nigerianus often extended up to the large intestine owing to its larger body size. Larger size of $P$. nigerianus was too obstructive to the gastro-intestinal tract of the infected individuals. The intestine appeared entirely blocked and continually contracted in affected individuals owing to massive size of the parasite. Digestive accessories like the liver had no infection of these acanthocephalans.

While identifications are usually made by comparing unknown sequences against the DNA barcodes of known species via distance-based tree construction sequence identification engine, the present sequence showed no homology identifications through BOLD and GenBank/NCBI. The closest Polyacanthocephala P. caballeroi (DQ089724) formed a common clade with these parasite sequences. Other classes; Archiacanthocephala, Palaeacanthocephala and Eoacanthocephala indicated a clear close species clade relationships with various members gene relationships in the GenBank/NCBI database. A data set of 36 taxa and bootstrap values (higher than 50\%) are presented on equivalent branches of the NJ tree where the relationships among classes of Acanthocephala were supported by high bootstrap values (Figure 1). The new sequences are deposited in GenBank/NCBI with accession numbers KC904074 and KC9040745.



Figure 1. NJ tree showing high bootstrap values on equivalent branches of the tree, with $P$. caballeroi forming a common clade with NG-01 P. nigerianus and NG-05 P. echiyensis. 
Out of 152 individual samples of $S$. batensoda comprising 91 males (59.8\%) and female 61 (40.1\%), 57 (37.5\%) and 54 (35.5\%) had co-infection of $P$. echiyensis and $P$. nigerianus respectively. The parasites mean size NG1 $237.58 \mathrm{~mm} \pm 30.34 \mathrm{~mm}$ of $P$. echiyensis was lower than NG5 $994.61 \mathrm{~mm} \pm 110.07 \mathrm{~mm} \quad P$. nigerianus (Figure 2). Similarly, out of 57 (37.5\%) hosts infected, 43 males (75.4\%) and 14 females $(24.6 \%)$ had $P$. echiyensis with total recovered parasites 222. Also, 54
(35.5\%), males 40 (74\%) and females 14 (25.9\%) had P. nigerianus and a total 114 parasites recovered. The overall prevalence was high; $37.5 \%$ for P. echiyensis whereas $P$. nigerianus had $34.8 \%$. The length groups in each case showed very young $<10 \mathrm{~cm}$ (2.0\%), and much older individual hosts above $21 \mathrm{~cm}$ (3.9\%) had least level of the infections, respectively. Conversely, $10 \mathrm{~cm}-13 \mathrm{~cm}$ and $14 \mathrm{~cm}-17 \mathrm{~cm}$ length groups had high levels of infections with highest within $10 \mathrm{~cm}-13 \mathrm{~cm}$ range (23.0\%).

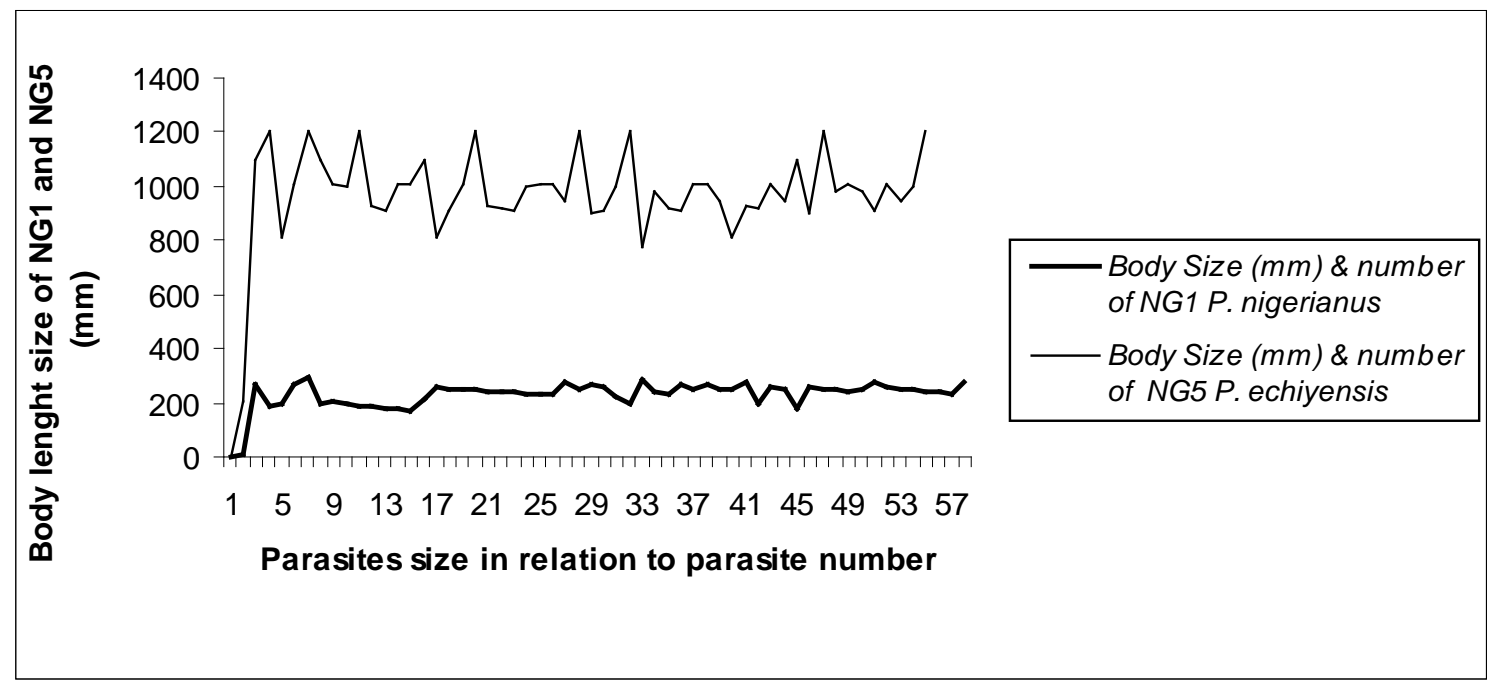

Figure 2. Parasite size and number in the hosts S. batensoda.

Although, fewer individual samples were caught by fishers during the dry season months, the occurrence of the parasites was distinctly more than during the rains. Though the trend of infection followed a similar pattern, NG5 had higher prevalence than NG1 with the highest prevalence 5.3\% in January. However, this similarity in the pattern of infection failed from March-July when the occurrence of NG1 had relatively much lower monthly prevalence $\leq 2.6 \%$ than NG5, i.e. $2.6 \%$, $2.6 \%, 2.0 \%, 2.0 \%, 3.3 \%$, respectively (Figure 3).

The abiotic factors, dissolved oxygen (8.0-14.0 mg. $\left.\mathrm{L}^{-1}\right)$ and $\mathrm{pH}$ (5.5-7.0) influenced the occurrence of the parasites. For instance, during floodplain fullness with higher oxygen concentration fewer parasites occurred whereas during habitat contraction and lower $\mathrm{pH}$ more parasites occurred (Table or Figure showing this data). However, the surface water temperature $\left(20.1-27.5^{\circ} \mathrm{C}\right)$ appeared not to show any perceptible effect. The occurrence of the parasites peaked when the water was slightly acidic $\mathrm{pH}$ (6.6-6.7) and dissolved oxygen approximately equal to 10.0 mg. $\mathrm{L}^{-1}$ which coincided with dry season months and floodplain contraction whereas lower infection rates were recorded during floodplain fullness when the water $\mathrm{pH}$ was 7.4-7.0 was definitely neutral and the oxygen content was approximately greater than 12 mg.L $\mathrm{L}^{-1}$ (Table.1). 


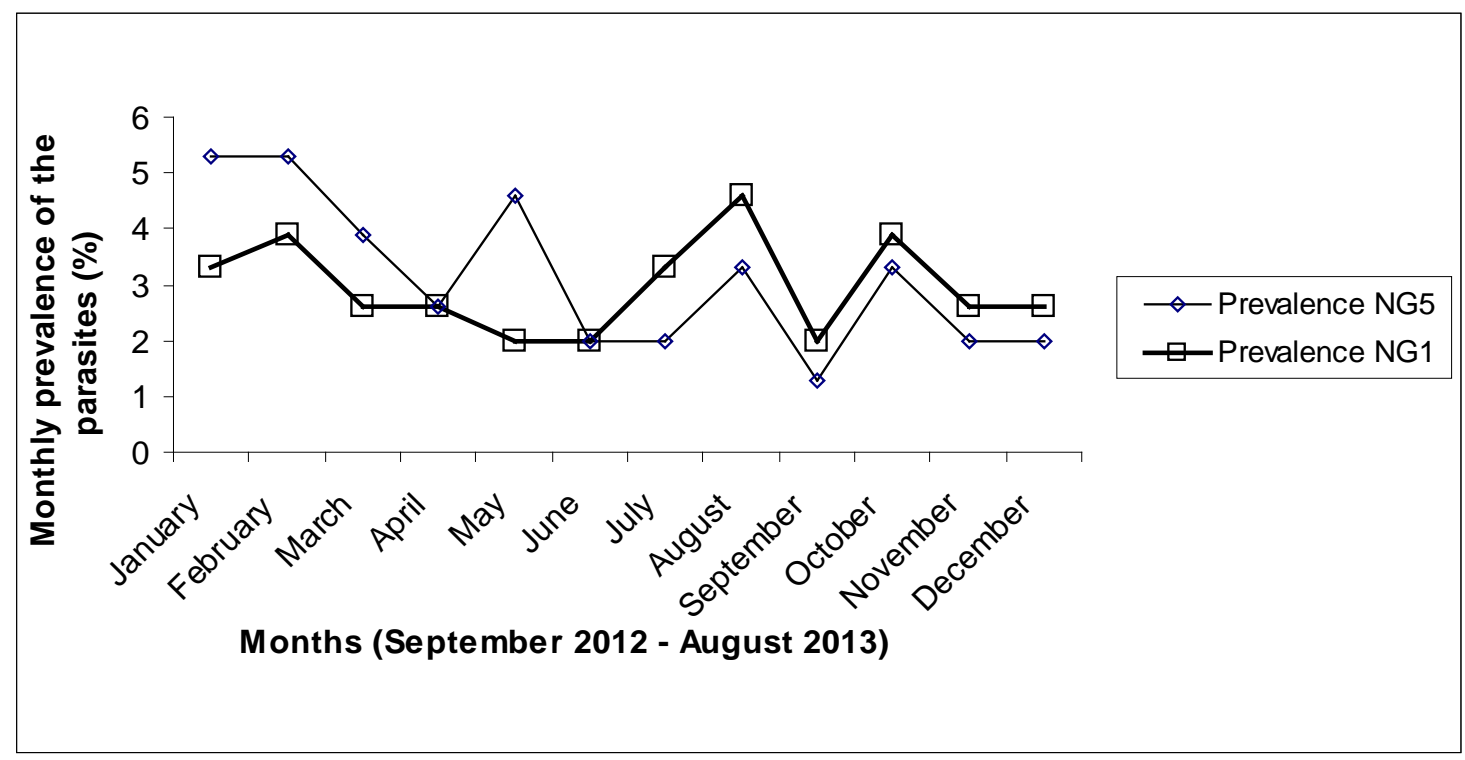

Figure 3. Seasonal occurrence of $P$. nigerianus and $P$. echiyensis.

Table 1. Monthly prevalence and physical environmental factors.

\begin{tabular}{|l|c|c|c|c|l|c|c|}
\hline Month & $\begin{array}{c}\text { Number of } \\
\text { parasites }\end{array}$ & $\begin{array}{c}\text { Prevalence } \\
\text { of NG1 }\end{array}$ & $\begin{array}{c}\text { DO } \\
\text { mgL }^{-1}\end{array}$ & $\mathbf{p H}$ & Month & $\begin{array}{c}\text { Number } \\
\text { of } \\
\text { Parasites }\end{array}$ & $\begin{array}{c}\text { Prevalence } \\
\text { of NG5 }\end{array}$ \\
\hline January & 16 & 3.3 & 10.0 & 6.6 & January & 37 & 5.3 \\
\hline February & 14 & 3.9 & 10.0 & 6.6 & February & 24 & 5.3 \\
\hline March & 10 & 2.6 & 10.0 & 6.6 & March & 16 & 3.9 \\
\hline April & 9 & 2.6 & 12.0 & 7.0 & April & 11 & 2.6 \\
\hline May & 5 & 2.0 & 14.0 & 7.2 & May & 22 & 4.6 \\
\hline June & 3 & 2.0 & 13.7 & 7.4 & June & 17 & 2.0 \\
\hline July & 11 & 3.3 & 13.2 & 7.4 & July & 13 & 2.0 \\
\hline August & 14 & 4.6 & 14.0 & 7.0 & August & 25 & 3.3 \\
\hline September & 6 & 2.0 & 13.0 & 7.0 & September & 5 & 1.3 \\
\hline October & 9 & 3.9 & 10.0 & 6.7 & October & 15 & 3.3 \\
\hline November & 7 & 2.6 & 9.8 & 6.7 & November & 21 & 2.0 \\
\hline December & 10 & 2.6 & 9.0 & 6.7 & December & 19 & 2.0 \\
\hline
\end{tabular}

\section{Discussion}

For the reasons that all organisms have access to limited energy cum other life dependent resources, there is a swap between the number and size of offspring; individuals so as to produce larger offspring are constrained to produce fewer, conversely those to produce smaller sized offspring produce larger numbers. Consequently, densities of microscopic organisms are much higher than macroscopic organisms. In effect, microscopic organisms tend to allocate more energy for reproduction to increase survival rate than larger organisms. In nature, the densities of a wide variety of organisms are highly correlated with body size. Therefore, in general, densities of animals and plants populations decrease with increasing size (Molles, 2002).

Temperature appeared not to exert much effect on the occurrence of the parasite species recovered. Seasonal 
occurrence of Acanthocephala in fish hosts differ among individual species hosts and their ecosystem (Chubb, 1982), for example, differences in hosts' diet habits, abiotic factors and adaptation to these changes by the intermediate and definitive hosts. However, there was no seasonality in the occurrence of P. kenyensis (Amin and Dezfuli, 1995), hitherto, the only known Polyacanthorhynchus sp in Africa. Nevertheless, seasonality influences fullness and contraction of aquatic ecosystems in Otuocha sampling port, Anambra River Basin.

Also, increased human activities along water banks have caused enormous and indiscriminate influx of refuse which could support infection in a contracted condition as infective larvae of parasites clump in patches of debris that form food materials of their hosts (Echi, 2005). Occurrence of the parasites was dependent on the habitat conditions which encouraged more detritus and it's clumping during dry season months than during rainy season months. The infective larvae in the food materials of the hosts were made available in the decaying organic matter contents of both fauna and flora origins. Infections of these acanthocephalan cystacanths maintained its definite infection cycle at early and late dry season months. Enormous detritus that influxes the river from heavy human activities such as rice mills, organic food materials etc along the banks collect and connect these infective larvae along with their hosts. Infection perhaps occurs at clumped portions where hosts' feeding activities were high.

\section{Conclusion}

Occurrence of the new sequences was season dependent based on the habitat conditions which encouraged more detritus and it's clumping during dry season months than during rainy season months. The differences in size of the new sequences produced differential parasitic effects on the hosts.

\section{Acknowledgements}

EPC is grateful to the Department of Science and Technology, Ministry of Science and Technology, Government of India and FICCI under the Prestigious C. V. Raman International Fellowship for African Researchers 2011-2012. EPC is also grateful to staff and students at the Rajiv Gandhi Center for Biotechnology, Thiruvananthapuram, India.

\section{Conflict of interest statement}

Authors declare that they have no conflict of interests.

\section{References}

Amin, O. M. Key to the families and subfamilies of Acanthocephala with the erection of a new class (Polyacanthocephala) and a new order (Polyacanthorhynchida). J. Parasitol., v. 73, p. 1216-1219, 1987. http://dx.doi.org/10.2307/3282307

Amin, O. M.; Dezfuli, S. B. Taxonomic notes on Polyacanthocephala kenyensis (Acanthocephala: Polyacanthorhynchidae) from Lake Naivasha, Kenya. J. Parasitol., v. 81, p. 76-79, 1995. http://dx.doi.org/10.2307/3284009

Bullock, W. L. Morphological features as tool and pitfall in acanthocephalan systematics. In: Schmidt, G. D. (Ed.). Problems in systematics of parasites. Baltimore, Maryland: University Park Press, 1969. p. 9-45.

Chubb, J. C. Seasonal occurrence of helminthes in freshwater fishes. Part IV. Adult Cestoda, Nematoda and Acanthocephala. Adv. Parasitol., v. 20, p. 1-292, 1982. http://dx.doi.org/10.1016/S0065308X(08)60539-4

Echi, P. C. The parasites of characids (Osteichthyes: Characidae) in Anambra River, Nigeria. Niger: Department of Zoology, University of Nigeria, and Nsukka, 2005. (M.Sc. Project reports).

Echi, P. C.; Ezenwaji, H. M. G. The parasite fauna of characids' (Osteichthyes: Characidae) Anambra River, Nigeria. Afr. J. Ecol., v. 48, no. 1, $\quad$ p. 1-4, 2010. http://dx.doi.org/10.1111/j.13652028.2009.01030.x 
Echi, P. C; Suresh, K.; Sanil, G.; Iyaji, F. O.; Nwani, C. D.; Ejere, V. C. Mitochondrial DNA resolution of two new sequences Polyacanthorhynchus echiyensis n. sp. and Polyacanthorhynchus nigerianus n. sp. (Polyacanthocephala: Acanthocephala) in a parentenic host from a tropical river. Env. Con. J., v. 16, no. 1/2, p.13-17, 2015.

Ivanova, N. V.; de Waard, J. R.; Hebert, P. D. N. An inexpensive, automation-friendly protocol for recovering high-quality DNA. Mol. Ecol. Notes, v. 6, no. 4, p. 998-1002, 2006. http://dx.doi.org/10.1111/j.14718286.2006.01428.x

Molles M. C. Ecology: concepts and applications. New York: McGraw Hill, 2002.

Nickol, B. B. Epizootiology. In: Crompton, D. W. T.; Nickol, B. B. (Eds.). Biology of the Acanthocephala. Cambridge: Cambridge University Press, 1985. p. 307-346.
Olaosebikan, B. D.; Raji, A. Field guide to Nigerian freshwater fishes. New Bussa: Federal College of Freshwater Fisheries Technology, 1998.

Schmidt, G. D.; Canaius, A. G. Acanthocephala from Kenya with descriptions of two new species. J. Parasitol., v. 53, no. 3, p. 634-637, 1967. http://dx.doi.org/10.2307/3276730

Tamura, K.; Peterson, D.; Peterson, N.; Stecher, G.; Nei, M.; Kumar, S. MEGA5: molecular evolutionary genetics analysis using maximum likelihood, evolutionary distance, and maximum parsimony methods. Mol. Biol. and Evol., v. 28, $\quad 2011$. http://dx.doi.org/10.1093/molbev/msr121 